NBER WORKING PAPER SERIES

\title{
THE IMPACT OF EMPLOYER MATCHING ON SAVINGS PLAN PARTICIPATION UNDER AUTOMATIC ENROLLMENT
}

\author{
John Beshears \\ James J. Choi \\ David Laibson \\ Brigitte C. Madrian \\ Working Paper 13352 \\ http://www.nber.org/papers/w13352 \\ NATIONAL BUREAU OF ECONOMIC RESEARCH \\ 1050 Massachusetts Avenue \\ Cambridge, MA 02138 \\ August 2007
}

The findings and conclusions expressed are solely those of the authors and do not represent the views of SSA, National Institute on Aging, the National Science Foundation, any other agency of the U.S. Federal Government, the RRC, or the NBER. We thank Hewitt Associates for their help in providing the data. We are particularly grateful to Pam Hess, Yan Xu, and Lori Lucas at Hewitt for their help with this project. Neel Rao provided excellent research assistance. We appreciate the helpful feedback of Dan McFadden, Olivia Mitchell, and seminar participants at the National Bureau of Economic Research. The authors acknowledge financial support from the National Institute on Aging (grant R01-AG021650) and the U.S. Social Security Administration (funded as part of the Retirement Research Consortium). Beshears acknowledges financial support from a National Science Foundation Graduate Research Fellowship.

(C) 2007 by John Beshears, James J. Choi, David Laibson, and Brigitte C. Madrian. All rights reserved. Short sections of text, not to exceed two paragraphs, may be quoted without explicit permission provided that full credit, including $(\mathrm{C}$ notice, is given to the source. 
The Impact of Employer Matching on Savings Plan Participation under Automatic Enrollment John Beshears, James J. Choi, David Laibson, and Brigitte C. Madrian

NBER Working Paper No. 13352

August 2007

JEL No. D14,D91,G23,H31,J32

\begin{abstract}
Existing research has documented the large impact that automatic enrollment has on savings plan participation. All the companies examined in these studies, however, have combined automatic enrollment with an employer match. This raises a question about how effective automatic enrollment would be without a direct financial inducement not to opt out of participation. This paper's results suggest that the match has only a modest impact on opt-out rates. We estimate that moving from a typical matching structure - a match of $50 \%$ up to $6 \%$ of pay contributed - to no match would reduce participation under automatic enrollment at six months after plan eligibility by 5 to 11 percentage points. Our analysis includes a firm that switched from a match to a non-contingent employer contribution. This firm's experience suggests that non-contingent employer contributions only weakly crowd out employee participation.

John Beshears

Department of Economics

Littauer Center

Harvard University

Cambridge, MA 02138

beshears@fas.harvard.edu

James J. Choi

Yale School of Management

135 Prospect Street

P.O. Box 208200

New Haven, CT 06520-8200

and NBER

james.choi@yale.edu

David Laibson

Department of Economics

Littauer M-14

Harvard University

Cambridge, MA 02138

and NBER

dlaibson@harvard.edu

Brigitte C. Madrian

John F. Kennedy School of Government

Harvard University

79 JFK Street

Cambridge, MA 02138

and NBER

Brigitte_Madrian@Harvard.edu
\end{abstract}


Companies have used a variety of approaches to encourage participation in employer-sponsored savings plans. The most common approach, the provision of an employer matching contribution, is now offered by the vast majority of large firms (Profit Sharing Council of America, 2006). Even with a match, however, savings plan participation rates are often surprisingly low (Choi, Laibson, and Madrian, 2005), and empirical studies of matching contributions' effect on plan participation have uniformly found relatively small effects (Andrews, 1992; Papke and Poterba, 1995; Papke, 1995; Bassett, Fleming, and Rodrigues, 1998; Kusko, Poterba, and Wilcox, 1998; Choi, Laibson, Madrian, and Metrick, 2002; Even and Macpherson, 2005; Duflo et al., 2006; Engelhardt and Kumar, forthcoming).

Automatic enrollment is an alternative mechanism for increasing savings plan participation. In a standard opt-in enrollment scheme, employees must actively elect to participate in the plan if they wish to contribute. In contrast, under automatic enrollment, employees are enrolled in their employer's savings plan at a default contribution rate and asset allocation unless they actively make an alternative choice. Relative to the standard opt-in approach, automatic enrollment dramatically increases plan participation, particularly among younger, low-tenure, and lower-income employees (Madrian and Shea, 2001; Choi, Laibson, Madrian, and Metrick, 2002, 2004; Beshears, Choi, Laibson, and Madrian, 2008). The participation rate increase at one year of tenure is as much as 60 percentage points.

All of the companies in which automatic enrollment has been studied to date have also offered an employer matching contribution. In principle, the match gives most employees a strong reason not to opt out of participation (and indeed, few do). But some extensions of automatic enrollment, such as the Automatic IRA proposal in the U.S., do not include a matching contribution. The extent to which automatic enrollment's effectiveness relies on the presence of a match is an open question. Without a match, the opt-out rate could be much higher, since participation incentives are greatly reduced. On the other hand, if employee inertia drives the automatic enrollment participation effect, we might expect high participation rates even without a matching contribution.

We estimate the employer match's impact on savings plan participation under automatic enrollment in two ways. First, we study a large firm (Company A) using 
automatic enrollment that replaced its employer match $(25 \%$ on the first $4 \%$ of pay contributed) with an employer contribution equal to $4 \%$ of pay plus an annual profitsharing contribution. The employer contribution in the new regime was not contingent on the employee's contributions. We find that among new hires with six months of tenure, savings plan participation rates decreased by at most 5 to 6 percentage points after the firm eliminated the employer match, and overall average employee contribution rates fell by $0.65 \%$ of pay.

Second, we pool data on savings plan participation at nine firms with automatic enrollment. We use variation in the match structure both across and within firms to identify the relationship between participation rates and the match. This analysis is potentially confounded by firm-level omitted variables but still offers suggestive evidence. We find that a one percentage point decrease in the maximum potential match as a fraction of salary is associated with a 1.8 to 3.8 percentage point decrease in plan participation at six months of eligibility. Thus, moving from a typical matching structure of $50 \%$ on the first $6 \%$ of pay contributed to no match at all would reduce savings plan participation under automatic enrollment by 5 to 11 percentage points. These results, along with those for Company A discussed above, lead us to conclude that automatic enrollment participation rates are positively related to match generosity, but the magnitude of this effect is modest.

Section I describes the savings plan and data for Company A. In Section II, we analyze the impact of Company A's change from a matching contribution to a noncontingent contribution. Section III examines the relationship between plan participation and the employer match amount at nine firms with automatic enrollment. Section IV concludes.

\section{Savings Plan and Data for Company A}

Company A is a Fortune 500 company in the information sector. We will consider this firm's employee savings outcomes from January 1, 2002 through December 31, 2005. Table 1 lists the salient features of Company A's 401(k) plan. Plan eligibility is restricted to employees aged 21 or older. Full-time employees who satisfy this age requirement are immediately eligible to participate, while part-time employees are 
eligible only after reaching one year of service and having worked 1,000 hours. Because of eligibility differences between full- and part-time employees, we restrict our analysis to full-time employees who are eligible for the plan. ${ }^{1}$ Throughout the sample period, fulltime employees were automatically enrolled in the 401(k) plan. After 30 days of service, employees who did not make an active enrollment election were enrolled at a contribution rate of $3 \%$ of salary allocated entirely to a money market fund. The plan offered six other investment options, including employer stock.

Until December 31, 2003, the company made matching contributions at a rate of $25 \%$ on employee contributions up to $4 \%$ of pay for employees who had attained at least one year of service and 1,000 hours of work (thus, the maximum possible employer match was $1 \%$ of pay). The maximum contribution rate over this time period was $25 \%$ of pay. On January 1, 2004, the company discontinued the employer match and replaced it with an employer contribution of $4 \%$ of pay plus an annual profit-sharing contribution that was not guaranteed in advance. In 2004 and 2005, this profit-sharing contribution was $5 \%$ of salary. The employer contributions in the new regime were not contingent upon the employee's contributions. The company also reduced the maximum employee contribution rate to $15 \%$ of pay at this time. Throughout the entire sample period, employees were also subject to IRS annual dollar contribution limits. ${ }^{2}$ Those employees classified as "highly compensated" for IRS non-discrimination testing purposes were potentially subject to stricter contribution rate limits, and for this reason we exclude them from the analysis below.

Our employee-level data come from Hewitt Associates, a large U.S. benefits administration and consulting firm. We have a series of year-end cross-sections of all Company A employees from 2002 through 2005. These cross-sections contain demographic information such as birth date, hire date, gender, and compensation. They also contain $401(\mathrm{k})$ variables such as the initial plan eligibility date, current participation

\footnotetext{
${ }^{1}$ We do not observe full- or part-time status directly in our data. In order to screen out part-time employees, we eliminate those who did not become eligible for the plan within two months of hire. Even though fulltime employees were immediately eligible upon hire, we keep employees with up to a two-month eligibility lag to allow for the possibility of administrative delays.

${ }^{2}$ In the sample we analyze, only eight out of 645 employees contributed enough in a year to plausibly be constrained by the IRS annual dollar contribution limits. The results we report below do not account for this censoring, but they are unaffected if we exclude these eight employees from the analysis.
} 
status, initial plan participation date, a monthly contribution rate history, and year-end asset allocation and total balances.

Our analysis compares two Company A employee cohorts. The "match cohort" contains plan-eligible full-time employees hired between January 1, 2002 and June 30, 2003. The "no-match cohort" contains plan-eligible full-time employees hired between January 1, 2004 and June 30, 2005. We exclude employees hired between July 1, 2003 and December 31, 2003 because these employees were hired under the old regime (employer match), but the point at which we measure participation and contribution outcomes for our analysis is after the switch to the new regime (a non-contingent employer contribution). Because our primary outcome variables - plan participation and employee contribution rates - are measured at six months of tenure, both cohorts are further limited to include only individuals whose employment at the company lasted for at least six months.

Company A made several significant acquisitions during our sample period. Unfortunately, our data do not identify those employees who joined the firm as a result of these acquisitions. To minimize the potentially confounding influence of these acquisitions, we make three further restrictions to our sample. First, we exclude employees who lived in states where the acquired companies were headquartered. Second, we exclude employees whose initial appearance in our dataset does not correspond to their year of hire (e.g., we exclude employees who are first observed in our data in the 2004 cross-section but who are listed as being hired before 2004). ${ }^{3}$ Third, we exclude employees whose hire dates are revised by more than one calendar month across different year-end cross-sections.

Our final sample contains 645 employees: 293 in the match cohort and 352 in the no-match cohort.

\footnotetext{
${ }^{3}$ We make one exception to this second criterion. There are 22 employees who first appear in our data in the year-end 2003 cross-section with December 2002 hire dates. We include these employees in the sample because their absence from the 2002 data is likely due to administrative delays in processing new employees at year-end rather than due to an acquisition.
} 


\section{Savings Plan Outcomes under Automatic Enrollment with and without an Employer Match: Company A}

We begin our analysis by comparing means across the match and no-match cohorts. We first consider plan participation, which we define as having a positive (nonzero) employee contribution rate. The first row of Table 2 shows that $89.1 \%$ of matchcohort employees were participating in the savings plan at six months of tenure. In contrast, the six-month participation rate for the no-match cohort is $80.7 \%$. This 8.4 percentage point difference in participation rates across the two cohorts is statistically significant and relatively stable from two months of tenure onward. The second row of Table 2 shows average employee contribution rates at six months of tenure (including non-participants with a contribution rate of 0 ). Given the decline in plan participation, it is not surprising that the average contribution rate also falls from $3.60 \%$ to $2.89 \%$ of salary after the elimination of the employer match. This $0.71 \%$ drop is statistically significant and driven both by the participation decline and a reduction in the average contribution rate conditional on participation from $4.04 \%$ to $3.58 \%$ of pay. The $0.46 \%$ drop in the conditional average contribution rate, however, is only statistically significant at the $10 \%$ level and is partly explained by the concurrent reduction in the maximum allowable contribution rate from $25 \%$ to $15 \%$ of pay.

Figure 1 shows the distribution of employee contribution rates at six months of tenure for the two cohorts separately. We see that the transition from the employer match to the non-contingent contribution was associated with a decrease in the fraction of employees contributing at most positive rates. ${ }^{4}$ More than two-thirds of employees in both cohorts contribute at the 3\% default contribution rate, consistent with previous research on how automatic enrollment affects the employee contribution rate distribution (Madrian and Shea, 2001; Choi, Laibson, Madrian, and Metrick 2002, 2004; Beshears, Choi, Laibson and Madrian, 2008). In contrast to previous research, we observe very few employees contributing at the $4 \%$ match threshold (only $2 \%$ of employees in the match cohort and $1 \%$ of employees in the non-match cohort for whom the match threshold is no longer relevant). There are several plausible explanations for why so few employees in

\footnotetext{
${ }^{4}$ The decline in the fraction of employees contributing at a rate greater than $15 \%$ in the non-match cohort is an artifact of the reduction in the maximum allowable contribution rate from $25 \%$ to $15 \%$ of pay that coincided with the switch from a matching contribution to a non-contingent contribution.
} 
the match cohort are at the match threshold. First, the employees at Company A are observed at only six months of tenure, which does not give them much time to switch from the default contribution rate to the match threshold (or another contribution rate of their choosing). Second, because the match threshold was only one percentage point above the default rate, participants' incentive to increase their contribution rate to the match threshold was much weaker than in other firms studied (Choi, Laibson, Madrian, and Metrick, 2005). Finally and perhaps most importantly, employees were not eligible to receive matching contributions until having completed one year of service, so most of the benefits from contributing at the match threshold did not accrue to employees at six months of tenure.

Of course, the transition from an employer match to a non-contingent contribution may have been accompanied by other changes at Company A that caused the savings plan choice differences between the two cohorts. Table 2 shows that relative to the nonmatch cohort, the match cohort was disproportionately female, somewhat older, and had a higher average salary. ${ }^{5,6}$ Not controlling for these differences could make the participation decline due to the employer match elimination look larger than it really was.

Table 3 shows the results of regressions that include demographic explanatory variables. The first two columns show the coefficients from a linear probability regression of savings plan participation at six months of tenure on an indicator for having been hired with an employer match in place, gender, age, and income in 2004 dollars. In column 1, we control linearly for age and income, whereas in column 2 we include age and income splines. ${ }^{7}$ The estimated 6.0 to 6.7 percentage point participation impact of having a match is statistically significant and somewhat lower than the raw 8.4 percentage point difference seen in Table 2. A probit specification (columns 3 and 4) yields estimated employer match marginal effects of 5.4 to 6.5 percentage points, also

\footnotetext{
${ }^{5}$ We deflated the salaries of employees in both cohorts to 2004 dollars using the growth in seasonally adjusted average weekly earnings for private sector workers from the Current Employment Statistics survey.

${ }^{6}$ Part of the difference in average age and income between the cohorts might be the result of an internship program that took place in the second half of the sample period. Compared to other employees, interns probably have weaker motives to participate in the $401(\mathrm{k})$ plan. To make sure that the presence of interns is not driving our results, we drop the 29 employees in the sample with incomes of less than $\$ 10,000$ and redo our analysis. The qualitative results do not change.

${ }^{7}$ The age spline has knots at 30,40 , and 50 years, and the income spline has knots at $\$ 20,000, \$ 40,000$, $\$ 60,000$, and $\$ 80,000$.
} 
statistically significant. Columns 5 and 6 list the marginal effects from a tobit regression of employee contribution rates which are censored below at zero and above at $25 \%$ (the match cohort) or $15 \%$ (the non-match cohort). Eliminating the employer match at company $\mathrm{A}$ is associated with a contribution rate decline of about $0.66 \%$ of salary, an effect that is statistically significant and only slightly less than the $0.71 \%$ raw effect in Table 2.

In summary, controlling for demographic differences between the match and nonmatch cohorts reduces but does not eliminate the estimated impact of the employer match under automatic enrollment. Note that these estimates represent the combined effect of removing the match and replacing it with a non-contingent contribution. The replacement of a match with a (relatively larger) non-contingent contribution generates a substitution effect that discourages employee contributions and a net income effect that also discourages employee contributions. Employee contributions are no longer subsidized and the employee has more total savings (employee plus employer contributions) for any given employee contribution. ${ }^{8}$ Our estimates provide an upper bound of the effects due solely to the removal of the employer match, since the simultaneous introduction of the non-contingent employer contribution generates an income effect that suppresses employee contributions. ${ }^{9}$

Our analysis also sheds light on the question of savings crowd-out. Our estimates provide an upper bound on the negative participation effects due solely to the introduction of the non-contingent contribution, since the simultaneous elimination of the match is likely to have discouraged employee participation. ${ }^{10}$

One limitation of many savings studies that use administrative data is the inability to address potentially offsetting (or reinforcing) changes in savings behavior outside of the account being studied. This caveat applies here as well. Employees have additional

\footnotetext{
${ }^{8}$ The employee loses a $25 \%$ match on contributions up to $4 \%$ of income but gains both a non-contingent employer contribution equal to $4 \%$ of income and a non-contingent profit-sharing contribution.

${ }^{9}$ On the other hand, there are some plausible reasons that the introduction of the non-contingent contribution could increase employee contributions. Employees might view it as a signal that their expected future income growth has fallen. Alternatively, employees could interpret the non-contingent contribution as implicit advice that their optimal savings rate is higher than they previously believed.

${ }^{10}$ A match unambiguously increases participation in a two-period model. Opposite effects are possible in models with more periods. However, the empirical literature on matching generally finds positive participation effects. Note that even in a two-period model, matching need not increase the average employee contribution due to the substitution effect.
} 
assets outside their 401(k) plan, and some employees also have other savings plan assets within Company A, which has an employee stock ownership plan (ESOP). However, most of the employees in our non-match sample are not eligible to participate in the ESOP (employees must have one year of service to be eligible). Moreover, the plan is non-elective; the company makes ESOP contributions on an annual basis to all employees who are eligible. With more years of data, it might be possible to assess the extent to which changes in ESOP balances across the two cohorts affect employees' 401(k) choices at company A. ${ }^{11}$ Unfortunately, the data are not presently available to undertake such an analysis, and we do not observe any other financial assets of this company's employees.

\section{Employer Matching Level and Savings Plan Participation under Automatic Enrollment at Nine Companies}

We now broaden our analysis to explore the relationship between the generosity of the employer match and savings plan participation under automatic enrollment at nine companies. We use variation in the employer match structure both within and across firms for identification. However, because of the potential existence of firm-level omitted variables, the results below must be interpreted with caution.

Table 4 describes the match structure at the nine companies used in our analysis. The match rate varies from no match at Company A (beginning in 2004 for the nonmatch cohort) to a $133 \%$ match on the first $6 \%$ of pay at Company I. Conditional on offering a match, the match threshold ranges from $2 \%$ of pay for employees with less than one year of tenure at Company $\mathrm{F}$ to $7 \%$ of pay at Company B. Two companies have changes in their employer match over our sample period: Company A (analyzed in Sections 2 and 3), which replaced its employer match of $25 \%$ on the first $4 \%$ of pay contributed with a non-contingent employer contribution in January 2004; and Company $\mathrm{B}$, which gradually increased its match rate from $60 \%$ to $62 \%$ to $65 \%$ on the first $7 \%$ of pay contributed.

\footnotetext{
${ }^{11}$ Madrian and Shea (2001), who first documented large participation increases following automatic enrollment in a 401(k) savings plan, find no evidence of offsetting savings behavior in the Employee Stock Purchase Plan (ESPP) of the company they studied.
} 
For this section's analysis, we use data that are identical in structure to the Company A data described in Section 2. We pool employees at the nine firms who are observed in at least one of the year-end cross-sections from 2002 through $2005 .{ }^{12}$ Our sample is limited to employees at these firms who meet the following criteria: they became eligible for their employer-sponsored savings plan between January 1, 2002 and June 30, 2005; they became eligible when they were between 21 and 65 years of age; they became eligible when automatic enrollment was in effect; and they did not leave the company within six months of becoming eligible. Unlike the analysis in Sections 2 and 3, we do not attempt to filter out part-time employees because we are unable to identify them for some of the companies. We also do not exclude "highly compensated" employees because we are only analyzing plan participation, a margin on which such employees do not face greater constraints than non-highly compensated employees.

To assess the relationship between the employer match and savings plan participation under automatic enrollment, we run a linear probability regression of savings plan participation at six months of eligibility on age, income in 2004 dollars, gender, and the generosity of the employer match. ${ }^{13,14}$ Our key dependent variable of interest is the maximum employer match (as a fraction of income) that a participant can receive by contributing at the match threshold and fulfilling all match-related service requirements, given the match structure in place at six months of eligibility. The maximum employer match does not necessarily correspond to the matching contribution an employee could receive after only six months of eligibility. For example, the maximum employer match as just defined at Company $\mathrm{D}$ is $4.2 \%$ of pay (a $70 \%$ match on the first $6 \%$ of pay), even though employees with less than one year of tenure can receive a match of at most $2.1 \%$ of pay (a $35 \%$ match on the first $6 \%$ of pay). Table 4 lists the maximum employer match used in our regression for each of the nine firms.

\footnotetext{
${ }^{12}$ Three firms did not have data available for all four years. We drop three additional firm-years because different employees within a company were offered different matches in these years and we are unable to identify which employees were offered which match.

${ }^{13}$ Even though our dependent variable is binary, we use a linear probability regression rather than a probit in order to facilitate the graphical display of the results in Figure 2.

${ }^{14}$ Instead of measuring participation at six months of tenure, as done earlier for Company A, we measure participation after six months of eligibility because some firms' employees are not immediately eligible upon hire. For most employees in the sample, however, six months of tenure and six months of eligibility are equivalent.
} 
Our employer match variable definition rests on the assumption that employees are forward-looking with respect to the match when making their decision about whether to opt out of savings plan participation under automatic enrollment. Given that the service requirement to obtain the maximum employer match is at most one year in our sample, we feel that this assumption is appropriate. Only three of our nine firms (Companies A, $\mathrm{C}$, and $\mathrm{H}$ ) have matches linked to tenure. We also assume that the match rate changes within companies A and B were surprises that were not known to employees in advance, since we define the maximum employer match using the match structure in place at the time we measure participation.

Because our maximum employer match variation is largely across-firm variation, we are precluded from putting firm-level fixed effects in these regressions. We do, however, calculate Huber-White standard errors with clustering at the firm level.

Column 1 in Table 5 gives the coefficient estimates from the regression described above when no other control variables are included. In this specification, decreasing the maximum employer match by $1 \%$ of salary is associated with a plan participation reduction at six months of eligibility under automatic enrollment of 2.8 percentage points. This is somewhat smaller than the 5 to 6 percentage point decline observed at Company A when it eliminated its employer match. However, as noted earlier, the Company A estimate is an upper bound on the true effect of match removal, since the match was replaced with a non-contingent employer contribution that is theoretically expected to decrease participation.

Figure 2 displays the regression results from the first column of Table 5 graphically. Every data point in Figure 2 corresponds to a group of employees that shares the same firm and maximum employer match (firms whose match changes over time are represented in the graph by more than one data point). The maximum match is on the $x$ axis, and the raw savings plan participation rate is on the $y$-axis. The regression line from the first column of Table 5 is also shown. Figure 2 shows that the positive relationship between the maximum match and participation estimated in Table 5 is robust and does not seem to be driven by outliers. 
In column 2 of Table 5, we add control variables, using linear splines for age and income as well as indicator variables for missing gender, age, and income data. ${ }^{15}$ The inclusion of demographic controls reduces the estimated impact of the employer match slightly: decreasing the maximum employer match by $1 \%$ of salary is associated with a 2.2 percentage point decline in participation, rather than the 2.8 percentage point decline shown in column 1.

Most of the individuals for whom gender, age or income data are missing come from three firms. Therefore, we restrict the sample in column 3 to the six firms for which we can construct demographic controls. ${ }^{16}$ When we run the regression without control variables - as in column 1 - on this restricted sample, the estimated impact of the employer match increases relative to that in column 1; participation declines by 3.8 percentage points when the maximum match decreases by $1 \%$ of pay. This suggests that there are some differences between the companies in our sample for which we do and do not have demographic data.

Finally, in column 4, we add the demographic control variables to the regression restricted to companies with demographic information. Just as in the full sample, adding demographic controls to this restricted sample reduces the estimated impact of the employer match. Across all of the specifications in Table 5, the coefficient on the maximum employer match ranges from 1.8 to 3.8 , indicating that decreasing the maximum employer match by $1 \%$ of salary reduces savings plan participation at six months of eligibility under automatic enrollment by 1.8 to 3.8 percentage points.

\section{Conclusions}

Automatic enrollment is an increasingly important feature of the retirement savings landscape. A recent survey of large U.S. firms found that $36 \%$ already automatically enroll new employees, and 55\% of firms without automatic enrollment say that they are very likely or somewhat likely to adopt it within a year (Hewitt Associates, 2007). To date, all the automatic enrollment savings plans that have been studied have

\footnotetext{
${ }^{15}$ The results are qualitatively similar if we use linear controls for age and income rather than splines.

${ }^{16}$ Even within those companies for which we have demographic information, some employees are nonetheless missing this information. We drop these employees with missing demographic data from the regressions in columns 3 and 4 .
} 
had an employer match. U.S. pension regulations encourage the use of matching through safe harbor clauses; firms can avoid non-discrimination testing if they have a sufficiently generous match. However, there is also has a safe harbor for non-contingent employer contributions. ${ }^{17}$

This paper aims to address how effective automatic enrollment might be in the absence of an employer match. Using two estimation strategies, one based on the substitution of the employer match with a non-contingent employer contribution, and the other based primarily on variation in the employer match across firms, we find that participation rates under automatic enrollment decline only modestly when the employer match is eliminated or reduced. The switch from a matching contribution to a noncontingent contribution at Company A caused the plan participation rate at six months of tenure to drop by 5 to 6 percentage points. In a sample of nine firms with automatic enrollment, decreasing the employer match amount by $1 \%$ of pay was associated with a 1.8 to 3.8 percentage point decrease in the plan participation rate at six months of eligibility. Collectively, these results imply that moving from a typical matching structure of $50 \%$ on the first $6 \%$ of pay contributed to no match at all would reduce savings plan participation under automatic enrollment by 5 to 11 percentage points. Interestingly, these results are similar to the employer match effect on participation estimated by Engelhardt and Kumar (forthcoming) in a sample of older employees, most of whom were not subject to automatic enrollment.

Therefore, the success of automatic enrollment at increasing participation in employer-sponsored savings plans does not appear to rely much on having an employer match. It thus seems likely that automatic enrollment will also be effective at increasing participation in other contexts that do not naturally lend themselves to a matching contribution.

These results also suggest that companies with automatic enrollment need not offer a match in order to achieve broad-based participation. However, the employer match may be valuable for reasons other than the inducement that it creates to participate. For example, as a tax-favored form of compensation, the employer match may be

\footnotetext{
${ }^{17}$ To obtain safe harbor status, the plan must provide either a matching contribution equal to $100 \%$ of contributions up to $1 \%$ of pay and $50 \%$ of contributions for the next $5 \%$ of pay, or a non-contingent contribution of $3 \%$ of pay.
} 
important in the recruiting and retention of employees even if it does not have a large impact on savings plan participation.

However, the experience of Company A suggests that some of purposes served by an employer match could be achieved with a non-contingent employer contribution as well. The merits of an employer match versus a non-contingent contribution likely hinge not only on their average impact on savings plan outcomes (e.g., lower participation with a non-contingent contribution), but also on their distributional impact. For example, a non-contingent contribution will likely increase total savings for those employees least inclined to save, but its effects elsewhere in the savings distribution are ambiguous, since a match tends to cause herding at the match threshold. This herding may either increase or decrease savings, depending on how high the match threshold is and what savings rate employees would have chosen in the absence of a match. 


\section{References}

Andrews, Emily S., 1992. "The Growth and Distribution of 401(k) Plans." In John Turner and Daniel Beller, eds. Trends in Pensions 1992 (Washington, D.C..: U.S.

Department of Labor, Pension and Welfare Benefits Administration), pp. 149-176.

Bassett, William F., Michael J. Fleming, and Anthony P. Rodrigues, 1998. "How Workers Use 401(k) Plans?: The Participation, Contribution, and Withdrawal Decisions." National Tax Journal 51, pp. 263-289.

Beshears, John, James J. Choi, David Laibson and Brigitte C. Madrian, 2008. "The Importance of Default Options for Retirement Savings Outcomes: Evidence from the United States," NBER Working Paper No. 12009. In Stephen J. Kay and Tapen Sinha, editors, Lessons from Pension Reform in the Americas (New York: Oxford University Press).

Choi, James J., David Laibson, and Brigitte C. Madrian, 2005. "\$100 Bills on the Sidewalk: Suboptimal Saving in 401(k) Plans." NBER Working Paper 11554.

Choi, James J., David Laibson, Brigitte C. Madrian, and Andrew Metrick, 2002. "Defined Contribution Pensions: Plan Rules, Participant Decisions, and the Path of Least Resistance." In James Poterba, ed., Tax Policy and the Economy 16, pp. 67114.

Choi, James J., David Laibson, Brigitte C. Madrian, and Andrew Metrick, 2004. "For Better or For Worse: Default Effects and 401(k) Savings Behavior." In David Wise, ed., Perspectives in the Economics of Aging (Chicago: University of Chicago Press), pp. 81-121.

Choi, James J., David Laibson, Brigitte C. Madrian, and Andrew Metrick, 2005. "Optimal Defaults and Active Decisions.” NBER Working Paper 11074.

Duflo, Esther, William Gale, Jeffrey Liebman, Peter Orszag, and Emmanuel Saez, 2006. "Savings Incentives for Low- and Middle-Income Families: Evidence From a Field Experiment with H\&R Block.” Quarterly Journal of Economics 121, pp. 13111346.

Engelhardt, Gary V. and Anil Kumar, forthcoming. "Employer Matching and 401(k) Saving: Evidence from the Health and Retirement Study." Journal of Public Economics.

Even, William E., and David A. Macpherson, 2005. "The Effects of Employer Matching in 401(k) Plans.” Industrial Relations 44, pp. 525-549.

Hewitt Associates, 2007. "Survey Findings: Hot Topics in Retirement 2007." Lincolnshire: Hewitt Associates LLC. 
Kusko, Andrea, James Poterba and David Wilcox, 1998. "Employee Decisions with Respect to 401(k) Plans." In Olivia Mitchell and Sylvester Schieber, eds., Living with Defined Contribution Pensions: Remaking Responsibility for Retirement (Philadelphia: University of Pennsylvania Press), pp. 98-112.

Madrian, Brigitte, and Dennis Shea, 2001. "The Power of Suggestion: Inertia in 401(k) Participation and Savings Behavior." Quarterly Journal of Economics 116, pp. 1149-1187.

Papke, Leslie E., 1995. "Participation in and Contributions to 401(k) Pension Plans." Journal of Human Resources 30, pp. 311-325.

Papke, Leslie E., and James M. Poterba, 1995. "Survey Evidence on Employer Match Rates and Employee Saving Behavior in 401(k) Plans.” Economics Letters 49, pp. 313-17.

Profit Sharing Council of America, 2006. $49^{\text {th }}$ Annual Survey of Profit-Sharing and 401(k) Plans (Chicago: Profit Sharing Council of America). 


\section{TABLE 1. 401(k) Plan Features at Company A}

\section{Eligibility}

Eligible employees

Eligibility to make employee contributions

Eligibility for employer contributions

Automatic Enrollment

\section{Contributions}

Employee contributions

Employer contributions

Match Vesting

Other

Loans

Hardship withdrawals

Investment choices
Age 21+

Full-time employees: immediately upon hire

Part-time employees: after 1 year of service and 1,000 hours

After 1 year of service and 1,000 hours

Full-time employees automatically enrolled after 30 days at a 3\% contribution rate allocated to a money market fund

Before $1 / 1 / 2004$ : up to $25 \%$ of pay

After 1/1/2004: up to $15 \%$ of pay

Before $1 / 1 / 2004$ : employer match of $25 \%$ on first $4 \%$ of pay contributed by employee

Starting 1/1/2004: non-contingent employer contribution of $4 \%$ of pay plus profit-sharing contribution

Immediate

Available

Available; limited to one per year

7 options including employer stock. 
TABLE 2. Summary Statistics on Savings Plan Outcomes and Demographic Characteristics for Employees at Company A

\begin{tabular}{|c|c|c|c|}
\hline & $\begin{array}{c}\text { Match cohort } \\
\text { (Hired 1/1/2002 } \\
\text { through 6/30/2003) }\end{array}$ & $\begin{array}{c}\text { Non-match cohort } \\
\text { (Hired 1/1/2004 } \\
\text { through 6/30/2005) }\end{array}$ & $\begin{array}{l}t \text {-statistic } \\
\text { for } \\
\text { difference }\end{array}$ \\
\hline \multicolumn{4}{|l|}{$\begin{array}{l}\text { Savings plan outcomes } \\
\text { (at six months tenure) }\end{array}$} \\
\hline Participation rate & $89.1 \%$ & $80.7 \%$ & 2.95 \\
\hline $\begin{array}{l}\text { Average contribution rate } \\
\text { (all employees) }\end{array}$ & $3.60 \%$ & $2.89 \%$ & 3.01 \\
\hline $\begin{array}{l}\text { Average contribution rate } \\
\text { (participants only) }\end{array}$ & $4.04 \%$ & $3.58 \%$ & 1.86 \\
\hline \multicolumn{4}{|l|}{ Demographic characteristics } \\
\hline Fraction female & $51.5 \%$ & $45.7 \%$ & 1.47 \\
\hline Average age & 33.21 & 31.83 & 2.07 \\
\hline Annual salary (2004 dollars) & $\$ 49,167$ & $\$ 40,343$ & 2.93 \\
\hline Sample size & $\mathrm{N}=293$ & $\mathrm{~N}=352$ & \\
\hline
\end{tabular}

Source: Authors' calculations. The sample includes non-highly-compensated, full-time, savings-plan-eligible employees. Growth in seasonally adjusted average weekly earnings for private sector workers from the Current Employment Statistics survey is used to deflate employee salaries to 2004 dollars. 


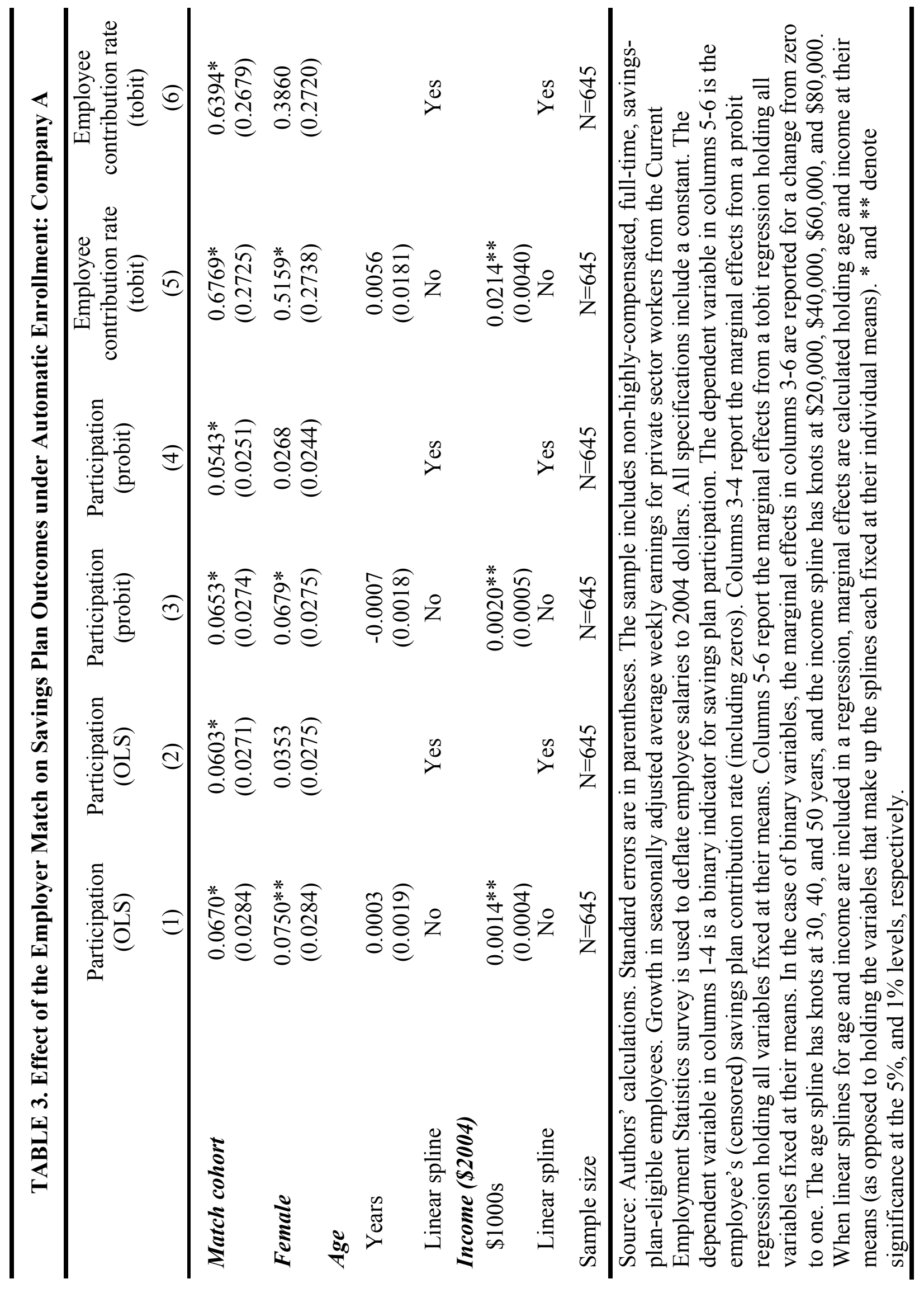




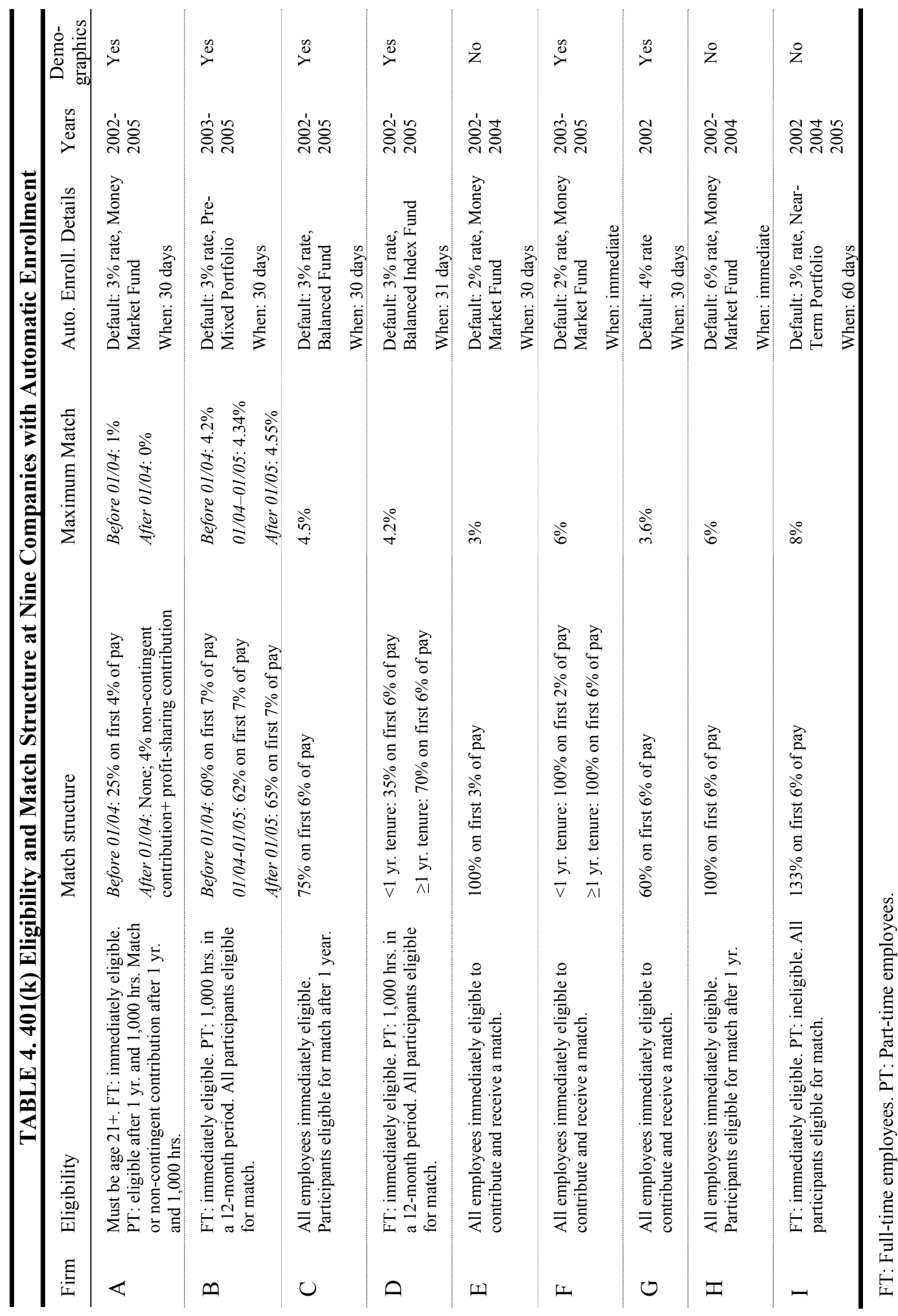


TABLE 5. The Effect of the Employer Match on Savings Plan Participation under Automatic Enrollment

\begin{tabular}{|c|c|c|c|c|}
\hline & $\begin{array}{c}\text { Full sample } \\
\text { (1) }\end{array}$ & $\begin{array}{c}\text { Full sample } \\
\text { (2) }\end{array}$ & $\begin{array}{c}\text { Companies } \\
\text { with control } \\
\text { data } \\
(3) \\
\end{array}$ & $\begin{array}{c}\text { Companies } \\
\text { with control } \\
\text { data } \\
(4) \\
\end{array}$ \\
\hline Maximum match & $\begin{array}{c}2.7818 * * \\
(0.6131)\end{array}$ & $\begin{array}{c}2.1995^{* *} \\
(0.3257)\end{array}$ & $\begin{array}{c}3.7519^{* *} \\
(0.2623)\end{array}$ & $\begin{array}{c}1.7784 * * \\
(0.4290)\end{array}$ \\
\hline \multicolumn{5}{|l|}{ Gender } \\
\hline Female & No & $\begin{array}{c}0.0021 \\
(0.0059)\end{array}$ & No & $\begin{array}{c}0.0075 \\
(0.0072)\end{array}$ \\
\hline Indicator for gender missing & No & $\begin{array}{l}-0.3254 \\
(0.6318)\end{array}$ & No & No \\
\hline \multicolumn{5}{|l|}{ Age } \\
\hline Linear spline & No & Yes & No & Yes \\
\hline Indicator for age missing & No & $\begin{array}{l}-0.4109 \\
(0.2125)\end{array}$ & No & No \\
\hline $\begin{array}{l}\text { Income (2004 dollars) } \\
\text { Linear spline }\end{array}$ & No & Yes & No & Yes \\
\hline Indicator for income missing & No & $\begin{array}{c}0.4882 * * \\
(0.1128)\end{array}$ & No & No \\
\hline Constant & $\begin{array}{l}0.7778^{* *} \\
(0.0271)\end{array}$ & $\begin{array}{c}0.1722 \\
(0.1254)\end{array}$ & $\begin{array}{l}0.7536^{* *} \\
(0.0028)\end{array}$ & $\begin{array}{c}0.2281 \\
(0.1265)\end{array}$ \\
\hline Sample size & $\mathrm{N}=44,279$ & $\mathrm{~N}=44,279$ & $\mathrm{~N}=35,895$ & $\mathrm{~N}=35,895$ \\
\hline \multicolumn{5}{|c|}{$\begin{array}{l}\text { Source: Authors' calculations. Huber-White robust standard errors with clustering by firm are } \\
\text { reported in parentheses. The sample includes savings plan eligible employees ages } 21-65 \text {. All } \\
\text { regressions are linear probability regressions. The dependent variable is a binary indicator for } \\
\text { savings plan participation. The maximum match is the maximum fraction of income an } \\
\text { employee can receive in matching contributions by contributing at the match threshold and } \\
\text { fulfilling all service requirements, given the match structure in place when the employee had } \\
\text { six months of } 401(\mathrm{k}) \text { eligibility. The coefficient on the maximum match represents the } \\
\text { percentage point increase in the participation rate when employees are offered an additional } \\
\text { one percent of their salary in matching contributions. The spline for age has knots at } 30,40 \text {, } \\
\text { and } 50 \text { years, and the spline for income has knots at } \$ 20,000, \$ 40,000, \$ 60,000 \text {, and } \$ 80,000 \text {. } \\
\text { Growth in seasonally adjusted average weekly earnings for private sector workers from the } \\
\text { Current Employment Statistics survey is used to deflate employee salaries to } 2004 \text { dollars. } \\
* * \text { denotes significance at the } 1 \% \text { level. }\end{array}$} \\
\hline
\end{tabular}


FIGURE 1. Distribution of Contribution Rates with and without an Employer Match at Six Months of Tenure: Company A

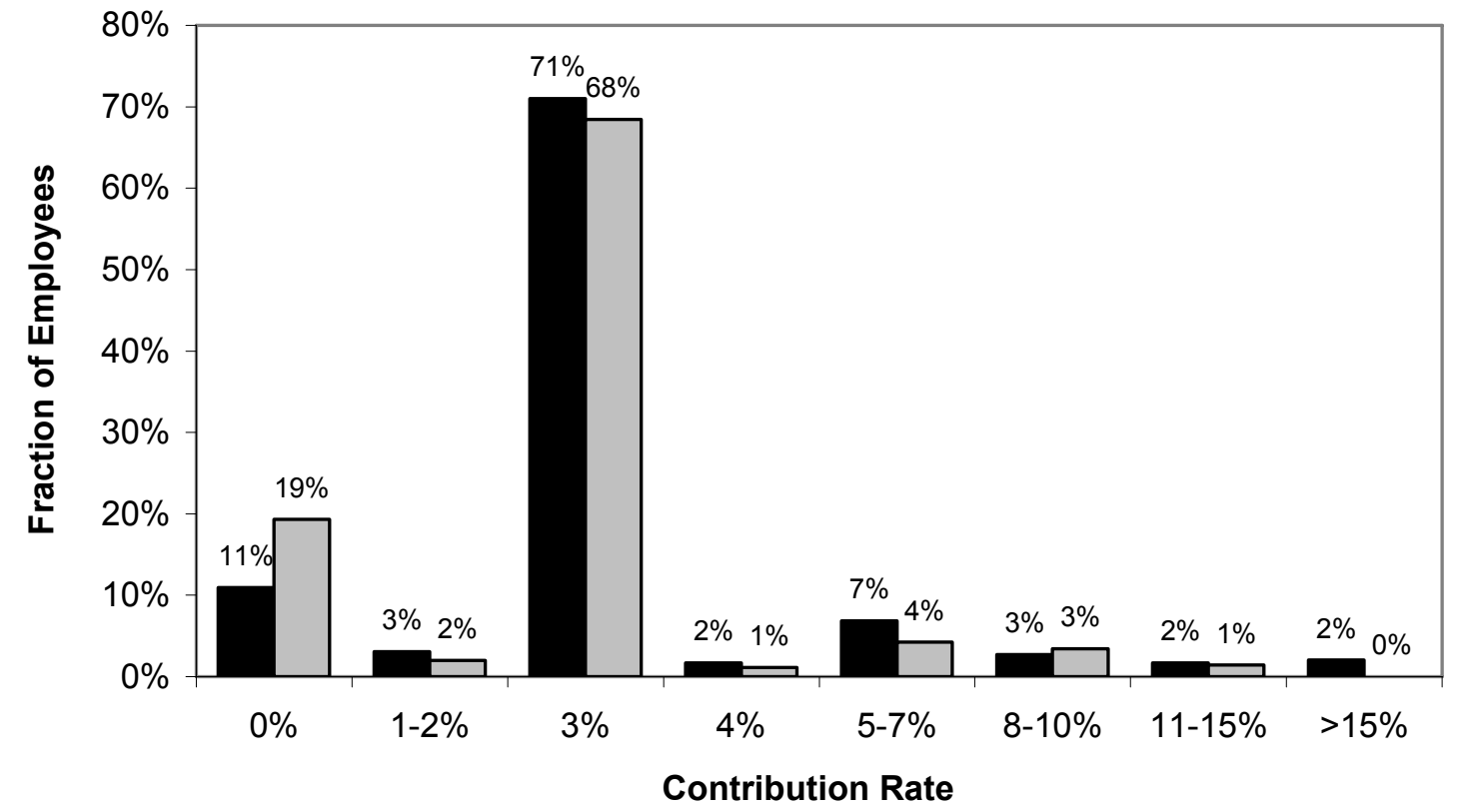

Match cohort

$\square$ Non-match cohort 
FIGURE 2. Relationship between the Employer Match and Savings Plan Participation under Automatic Enrollment at Nine Firms

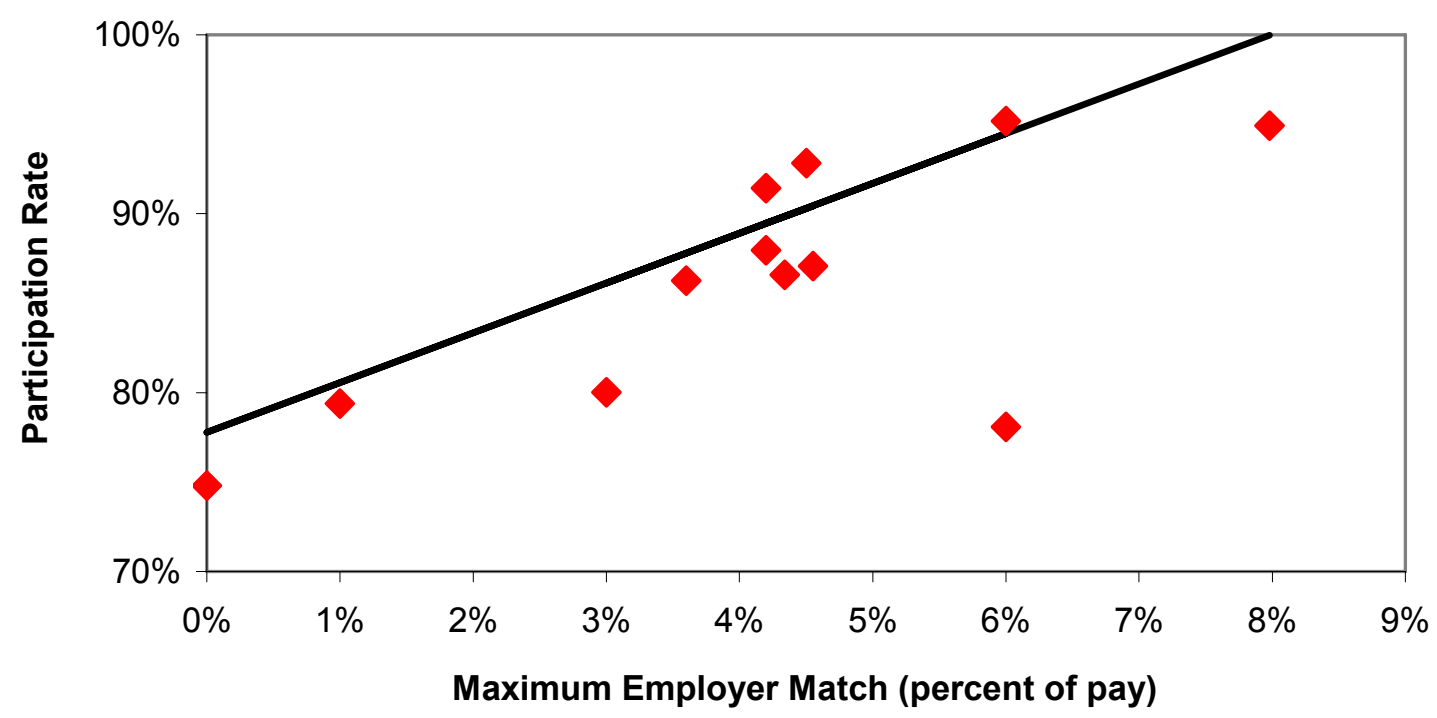

Note: Each point represents the raw participation rate among individuals who are employed by a given firm with the specified match amount. Participation is defined as having a positive employee contribution rate at six months of eligibility. The match amount is defined as the maximum fraction of income an employee can receive in employer matching contributions by contributing at the match threshold and fulfilling all service requirements, given the match structure in place when the employee had six months of 401(k) eligibility. The slope and intercept of the fitted line are given by the coefficients on the match amount and the constant in column 1 of Table 5. 